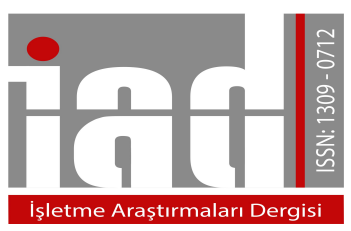

\author{
İşletme Araştırmaları Dergisi \\ Journal of Business Research-Turk \\ 10/3 (2018) 732-746
}

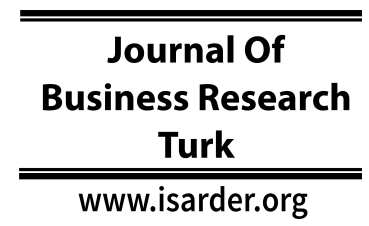

\title{
The Individual Antecedents of Impulsive Behavior
}

\author{
Pelin KANTEN \\ Çanakkale Onsekiz Mart University \\ Faculty of Political Science \\ Business Administration \\ Çanakkale, Turkey \\ orcid.org/0000-0002-6487-0203 \\ pelinkanten@,comu.edu.tr
}

\begin{abstract}
This study aims to investigate some individual antecedents of impulsive behavior. Within the literature, studies suggest that dark side of personality and self-efficacy belief considered an effective factors on employees' impulsive behaviors. For this purpose, the data were collected via survey method from 201 employees who are working in four and five star hotels in Antalya and Bursa provinces. Accordingly exploratory and confirmatory factor analyses, correlation and structural equation modelling were used for the data analyses. The results of the study indicate that while psychopathy has a significant and positive effect on employees' impulsive behaviors, narcissism has a significant and negative effect on the impulsivity. However, Machiavellianism has no significant effect on impulsive behaviors. On the other hand, it is found that self-efficacy has a significant and negative effect on employees' impulsive behaviors.
\end{abstract}

Keywords: Impulsive Behavior, Dark Personality Traits, Self-Efficacy

\section{INTRODUCTION}

In recent years, it is observed that impulsivity has become the center of the applied psychological research and behavioral sciences (Massie, 2006: 2). Due to the impulsivity regarded as a trigger component of many psychiatric disorders and clinical concerns, it has drawn researchers' attention (Farmer and Golden, 2009:12). In particular, because of the vital role of controlling impulses, impulsivity has been recognized by many of psychological areas including abnormal psychology, cognitive psychology, developmental psychology, neurogenetics, psychopharmacology and social psychology (Stahl et al., 2014: 850). However, impulsivity plays a crucial role in daily life of humans such as decision-making process, personality disorders, substance use disorders, attention deficit, hyperactivity disorder and etc. (Herman et al., 2018: 29). Scholars suggested that impulsivity reproduces the psychological factors which may lead to individuals' crime tendency, risk-taking, anti-social and aggressive behaviors. Therefore, based on the huge importance of impulsivity in several disciplines, researchers have difficulty in conceptualization of this construct. While some of them 
defines impulsivity as a risk-taking behaviors, others have conceptualized as a specific personality trait (Lynam and Miller, 2004: 319-320). As a trait, impulsivity refers to the enduring and distinct characteristics of individuals, which effect individuals' daily activities in their lives in a consistent manner and lasting over time. On the other hand, it is seen that impulsivity examined as a state which refers to the changing attitudes and momentary responses based on the internal and external stimulus (Nguyen et al., 2018: 67). In literature, it is suggested that internal and external stimulus or response tendencies lead to the spontaneous behaviors, which are labelled as impulsive attitudes. Besides, it is asserted that impulsivity generally characterized as a harmful behavior in society and has a mutual interaction with the psychological disorders (Stahl et al., 2014: 850).

While impulsive behaviors cause some unfavorable conditions, several psychopathic personality traits may lead to the impulsivity at the same time as well. In this context, it can be said that there are some underlying reasons of the impulsivity which are called as individual differences such as gender, age, education level and marital status and several personality characteristics like big five, dark traits, selfefficacy, locus of control and self-esteem. Accordingly, it is possible to express that there are some individual components, which are considered as antecedents of impulsive behaviors. Therefore, in this study, scope of the individual antecedents' dark personality traits and self-efficacy are investigated. The aim of this study is to determine the individual antecedents of the impulsive behaviors of hotel employees. Specifically, hotel industry requires employees to have favorable personality traits and positive attitudes, and behaviors which are crucial at interacting with customers. Thus, it can be inferred that understanding the importance of personality traits and behaviors are considerable in the hotel industry. Because, for providing service quality and customer satisfaction needed to employ individuals who possess positive traits and behaviors. Due to the harmful and unfavorable behaviors have a key role on the hotel industry, this research tested on this sample. Thus, this study aims to fill this gap in the literature by investigating the antecedents of impulsive behaviors of employees in the hotel industry.

\section{LITERATURE REVIEW}

\subsection{Impulsive Behaviors}

Impulsivity has been evaluated as a complex and multidimensional construct by the researchers. However, researchers have difficulty in defining impulsivity due to both it's viewed as specific personality trait and reflects some aspects of individual behaviors at the same time (Herman et al., 2018: 31). In the literature, it is seen various definitions of impulsivity exist, and one of the widely accepted definition is given "as a tendency to rapidness, to response with an unplanned activities based on the internal and external stimuli and to ignore the unfavorable consequences (Stanford et al., 2009: 385; Garofalo et al., 2018: 187). According to this definition, impulsivity represents making decisions quickly, lack of planning, proactivity and foreseeing and a consciousness to risk-taking (Herman et al., 2018: 31). In other words, it is also defined as an incapability to wait, a predisposition to act without thinking and forethought, insensitivity to the probable consequences (Reynolds et al., 2006: 306). However, researchers suggested that individuals are obliged to exhibit impulsive actions under some conditions. For example, individuals may suddenly break and maneuvering a car while driving in order to avoid an object on the road. These actions are regarded as impulsive behaviors, which 
include a little proactivity and forethought. On the other hand, these behaviors can be considered adaptive and useful in many complex situations due the necessity of sudden and quick response. For this reason, researchers have suggested that impulsivity includes some positive characteristics such as sensation-seeking, risk taking, excitement and reward seeking, venturesomeness, adventurousness and hyperactivity. Conversely, it is asserted that impulsive behaviors emerge based on the certain traits as lack of planning, lack of future orientation, lack of attention, recklessness, eagerness, desperateness, low anxiety and low self-control (Farmer and Golden, 2009: 12-13).

From this point of view, it can be inferred that impulsivity may be conceptualized as both dysfunctional and functional. While dysfunctional impulsivity involves lack of self-control and unplanned actions, functional impulsivity comprises of a tendency to having thrill-seeking, excitement seeking, sensation-seeking and extroversion (Justice, 2006: 7-8). In this context, it is possible to express that functional impulsivity represents the spontaneous behavior, which may be useful to making quick decisions in the case of scant time and restricted resources (Herman et al., 2018: 31). In literature, there are various attempts that have been done by the scholars to clarify classification of impulsivity. For instance, Eysenck and Eysenck (1977) examined impulsivity under four dimensions which are labelled as narrow impulsiveness, risk-taking, lack of planning, and liveliness. Zuckerman and colleagues (1991) have evaluated impulsivity in scope of the general model of personality. They determined that impulsivity involves lack of planning, a tendency to act without forethought and thrill-seeking (Whiteside and Lynam, 2001: 670-671). Moreover, Whiteside and Lynam (2001) subdivided impulsivity a four dimensions such as urgency or impatience, lack of premeditation/planning, lack of perseverance, and sensation-seeking. Urgency or impatience refers to the individuals' predisposition to act on strong responses when they faced with negative situations. Lack of premeditation or lack of planning is called as actions of individuals that includes indiscretion and unpredictability. Lack of perseverance refers to an individual's incapability to remain focused on when they encounter with the complex and boring tasks. The last dimension, sensation-seeking, shows a tendency to look for adventure experiences, which may be exciting, risky and hazardous (Churchill and Jessop, 2011: 259).

\subsection{Dark Personality Traits}

Due to the fact that personality traits have a crucial role in influencing the attitudes and behaviors of the individuals in the organizational processes, it is needed to take consideration of the positive and negative aspects of personality. Nowadays, organizations and researchers are aware that they should not only assess the positive aspects of personality but also focus on the negative aspects of it due to its harmful effects. In particular, as to the increase in unethical practices in business life over time, researchers in the management field have begun to focus on the dark side of personality (Heijnis, 2009: 4). However, because of the public scandals such as Enron, Lehman Brothers, Worldcom, Freddie Mac, Bernie Madoff, researchers have drawn attention to the dark personality traits in working life (Jonason et al., 2015: 112). Dark personality traits are regarded as significant characteristics that are undesirable and unfavorable in the social life because of its negative effects on individuals' attitudes and behaviors (Jonason et al., 2010: 373). In literature, there is no universally accepted classification of the dark trait personality in organizational and management research. For example, while Kowalski (2001); Paulhus and Williams (2002); Wu and LeBreton (2011); 
O'Boyle et al. (2012) examined dark personality traits under three distinct dimensions such as narcissism, machiavellianism, and psychopathy. Hogan and Hogan (2001); Moscoso and Salgado (2004) classified dark traits based on the DSM IV- Axis II disorder, which is one of personality disorders (Kaiser et al., 2013: 4).

Majority of the researches have evaluated these traits commonly as a machiavellianism, narcissism, and psychopathy. Machiavellianism is defined as a manipulative personality, which represents lack of empathy, low affect, low empathy, having an unethical thought and views, and having a tendency to deception and exploitation of others and being self-obsessed (Spain et al., 2014: 42). In addition, machiavellianism refers to the some certain characteristics such as blaming others, emotional coldness and self-seeking. Narcissism is defined as being self-centered and possessing some features like arrogance, grandiosity, superiority and selfishness (Wai and Tiliopoulos, 2012: 794-795). Narcissist individuals need for attention and admiration by others, like vanity and uniqueness, strive to obtain high status, power and prestige (Rauthmann and Kolar, 2013: 582). Due to the its characteristic such as lacking trust, paying no attention and caring others, narcissists have difficulty in building social relationships (Spain et al., 2014: 43). The ultimate dimension of psychopathy refers to the antisocial behaviors and emotions, and psychopaths also show tendency to have low affect, low remorse, low fear, low empathy, high egocentrism, impulsivity and aggression (Jonason et al., 2012: 194). Moreover, psychopathy can be examined as a predisposition, which leads to exhibit self-interested attitudes and behaviors for achieving individuals' goal in their both social and work life (Koehn et al., 2018: 1). Consequently, the dark traits, which represent undesirable features of individuals, are considered distinctive and also it has overlapped components which lead to some behaviors such as unethical, manipulative, impulsiveness, egocentric, accusing and etc. (Modic et al., 2018: 2). Besides, it is suggested that dark personality traits lead to several negative attitudes and behaviors like aggression, hostility, deviance, violence and deception (O’Boyle, Jr. vd., 2012: 557).

\subsection{Self-Efficacy}

Self-efficacy is regarded as a specific personality trait or a characteristic, which is derived from the Bandura's social cognitive theory. Social cognitive theory reveals that self-efficacy is considered a self-regulatory mechanism that facilitates handling the motivation levels and actions of individuals (Kanten, 2014: 117). However, selfefficacy refers to the self-perceived capabilities and confidence to perform tasks and activities effectively and achieving goals smoothly (Bausch et al., 2014: 172). In addition, Bandura (1997) defined self-efficacy as an individual's belief in his or her capacity to regulate the cognitive, motivational, and behavioral resources, which are required to perform successfully (Song and Chon, 2012: 799). In other words, because self-efficacy represents the confidence that leads to exercising control over both social and work life of individuals, it is considered a vital component in the development of human behaviors (Borgogni et al., 2013: 130). Besides, researchers suggested that selfefficacy may have significant effect on individuals' thoughts, feelings, views and emotional reactions. For example, when individuals have a high self-efficacy, they may take actions and act in order to solve problems. Moreover, they manage their actions and do not react immediately to their environment based on the high self-efficacy (Simosi, 2012: 95). 
In the literature, it is expected that self-efficacy may have significant influence on individuals' choices, success levels, performances and persistence of their actions. Otherwise, prior researchers emphasized that self-efficacy affects some organizational outcomes such as work performance, finding job, organizational productivity, learning, choice of career and career advancement (Iskandar and Sanusi, 2011: 32). Together with its benefits, it is possible to express self-efficacy as an important determinant of all organizational behaviors. Because it is viewed as a self-regulatory mechanism which influence behavior and attitudes, perception of problematic situations and challenges. Due to the self-efficacy reflects individuals' confidence which makes them easier to cope with problems, to lead managing emotions, stress, anger and anxiety in a good manner. Besides, individuals do not have a tendency to withdraw from the difficult situations that they encountered (Borgogni et al, 2013: 130). As a result, self-efficacy triggers individuals to put more effort forth, to explore opportunities in their environment and facilitates to handle stressful conditions effectively so it provides positive outputs both for individuals and organizations (Kanten, 2014: 117).

\section{RESEARCH MODEL AND HYPOTHESES}

In hotel industry, due to the global and competitive conditions, employees need to maintain face-to- face communication with the customers for the survival and success of organizations. Hotel employees are considered an important component for handling the customers' requests, complaints and demands (Karatepe, 2012: 495). However, hotel employees also play a vital role for attaining customer satisfaction, customer loyalty and service quality. By enabling employees to provide favorable outcomes and providing to exhibit positive attitudes, they should be managed effectively (Jha and Nair, 2008: 147). Besides, the desirable behaviors and attitudes, which are expected from the employees, highly depends on the personality characteristics. In other words, it is required to determine effectively which personality traits are suitable in order to obtain service quality. To increase customer satisfaction and organizational performance, personality traits should match with the demands of hotel industry. Moreover, recognizing personality characteristics leads to anticipating, estimating and controlling of attitudes and behavior of employees (Jovičić et al., 2011: 119-122). In particular, it is suggested that the dark side of personality plays a crucial role on the attitudes and behaviors of individuals in work and social life. Therefore, it can be inferred that individuals with dark personality traits are expected to exhibit negative attitudes and behaviors. Nevertheless, it is inevitable to encounter individuals who have dark or unfavorable personality traits. In this context, negative attitudes and behaviors should be eliminated for the succession of the organizations (Kanten et al., 2015: 367).

Impulsivity is one of the negative and undesirable behaviors in the society, which emerges based on individual differences. Frequently, it is suggested that impulsive behaviors are related with the symptoms of several disorders such as hyperactivity, attention-deficit, borderline personality disorder, anti-social personality disorder and dark traits (Stanford, 2009: 385). In literature, some studies Jones and Paulhus (2011); Crysel et al., (2013); Justice (2016); Malesza and Ostaszewski (2016) indicated that dark trait personality components which are called narcissism, machiavellianism, and psychopathy have significant effect on impulsivity behaviors of individuals. Specially, psychopathy is generally characterized as high impulsivity and a tendency to behave inappropriately, and in an unethical manner (Wai and Tiliopoulos, 2012: 795). While psychopaths easily exhibit impulsive acts, are not concerned with their social 
environment and do not care their reputations, machiavelists give greater importance to their reputation and avoid actions which may affect them harmfully. Therefore, because machiavelists are more strategic than psychopaths, it is expected them to control their behaviors and have a little disposition to act in an impulsive manner (Jones and Paulhus, 2014: 29). However, Jones and Paulhus (2011) suggested that while psychopathy is related with dysfunctional impulsivity, narcissism issignificantly correlated with the functional impulsivity. Besides, due to the machiavelists have strong self-interests and self-control, they refrain from exhibiting impulsive behaviors. (Malesza and Ostaszewski, 2016: 198). In this context, since it is possible to express that dark trait elements such as narcissism, machiavellianism, and psychopathy are considered antecedents of impulsive behaviors, and the following hypotheses are proposed:

$\mathrm{H}_{1}$ : Narcissism influences employees' impulsive behaviors.

$\mathrm{H}_{2}$ : Machiavellianism influences employees' impulsive behaviors.

$\mathrm{H}_{3}$ : Psychopathy influences employees' impulsive behaviors.

Self-efficacy represents a mental process, which directs thoughts, attitudes, and behaviors, and also has a vital role on individuals' motivation levels, attainment of the objectives and their resilience and tolerance levels in the face of challenges (Vasconcelos et al., 2018: 1). However, self-efficacy is called as individual differences, which plays a significant role on achieving tasks, work-relatedness and cognitive task performance (Rosen, 2010: 9). In other words, individuals who show high self-efficacy have a more positive affect towards their work roles and also possess strong belief that they can control outputs. On the other hand, individuals who have high self-efficacy are less likely to exhibit negative behaviors such as deviant and etc. (Tüzün et al., 2017: 394). In the literature, it is observed that self-efficacy may have some adverse effects. For example Gambin and Święcicka (2015) asserted that self-efficacy belief has a weak correlation with hyperactivity, attention deficit and impulsivity. Simmen-Janevska et al., (2012) suggested that self-efficacy which is considered a self-regulatory mechanism facilitates individuals' problems solving and suppresses their impulsive reactions. Therefore, it can be said that self-efficacy is examined as one of the antecedents of impulsive behaviors, the following hypothesis is proposed:

$\mathrm{H}_{4}$ : Self-efficacy belief influences employees' impulsive behaviors.

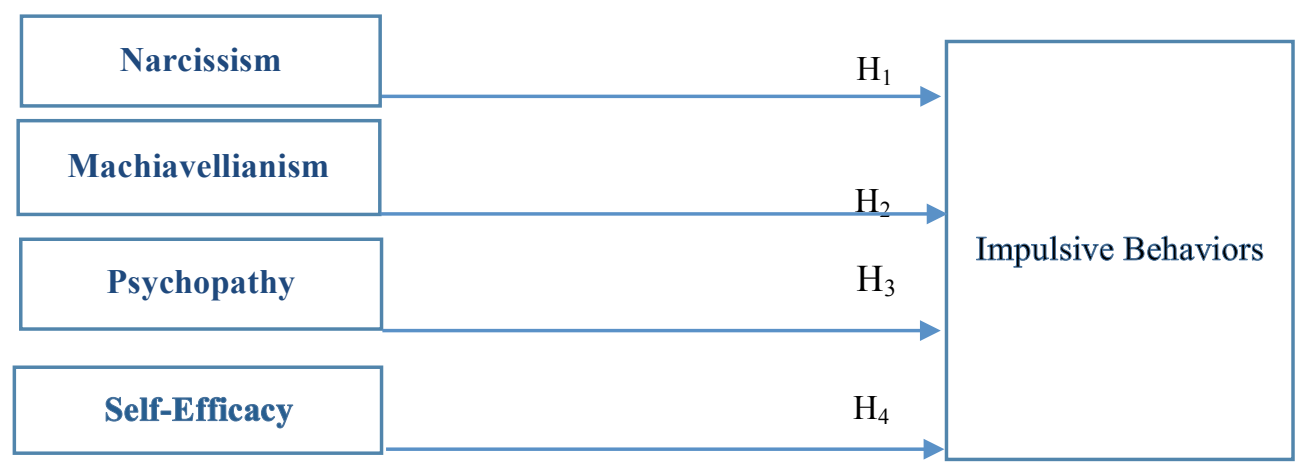

Figure 1. Research Model 


\section{RESEARCH METHOD}

\subsection{Sample And Procedures}

The sample of the present research was composed of four and five star hotels, which are located in Bursa and Antalya. The participants of this study consist of 201 employees who have been working for four different hotels which are determined via convenient sampling method. Out of 280 questionnaires that have been sent out, 250 of them have returned, representing a response rate of $83 \%$. After the elimination of the cases such as incomplete data and outliers, 201 questionnaires $(71 \%)$ have been accepted as valid and were included in the evaluations. However, questionnaire survey method was used for data collection in this study. The questionnaire form contains three different measures related to research variables.

\subsection{Measures}

The measures used in the questionnaire forms have been adapted from the previous studies in the literature. All measures have been adapted to Turkish by the lecturers and a pilot study has been conducted for the validity of these measures. Before the distribution of the survey to the actual sample, a pilot study was conducted in order to determine whether the questions would be understood properly and to check the reliability of the scales. As a result of the pilot study, some corrections were made in the questionnaire forms. A Likert-type metric, that is, expressions with five intervals has been used for answers to the statements of survey. Anchored such; "1- strongly disagree, 2- disagree, 3- agree or not agree, 4- agree, 5-strongly agree". Moreover, 6 demographic questions were included in the questionnaire form. All of the research scales were subjected to the exploratory factor analyses to check the dimensions, and then confirmatory factor analyses were applied to all scales.

- Dark Personality Traits Scale: Employees' dark personality trait tendencies were measured with 25 items from Jones ve Paulhus (2014) study. Exploratory factor analysis using principle component analysis with varimax rotation was applied to the adapted scale to check the dimensions. As a result of the varimax rotation of the data related to the dark personality traits variables, 14 items were removed from the analysis due to the factor loading that are under 0.50. Additionally, three factor solutions; (machiavellianism, narcissism, and psychopathy) were obtained in accordance with the theoretical structure. Some examples of the items asked to the employees are as follows: "Avoid direct conflict with others because they may be useful in the future"; "I know that I am special because everyone keeps telling me so"; "People often say I'm out of control".

- Self-Efficacy Belief Scale: Employees' self-efficacy belief levels were measured with 10 items that were developed by Schwarzer and Jerusalem (1995). As a result of the exploratory factor analysis related to the self-efficacy variables, three items were removed and one factor solution was obtained per theoretical structure. Some examples of the items asked to the employees are as follows: "I can always manage to solve difficult problems if I try hard enough"; "I can usually handle whatever comes my way".

- Impulsive Behavior Scale: Employees' impulsive behavior levels were measured with 25 items which were taken from Magid and Colder's (2007); Cyders et al's., 
(2014) studies. As a result of the exploratory factor analysis related to the impulsive behavior variables, 4 items were removed from the analysis due to the factor loadings under 0.50 and four factor solutions (negative urgency, lack of perseverance, lack of premeditation, and sensation-seeking) were obtained per theoretical structure. Some examples of the items asked to the employees are as follows: "I welcome new and exciting experiences and sensations, even if they are a little frightening and unconventional"; "When I am upset I often act without thinking"; "I enjoy taking risks".

Table 1: Summary Table of Exploratory Factor and Reliability Analyses

\begin{tabular}{|c|c|c|c|c|c|}
\hline $\begin{array}{l}\text { Dark Personality } \\
\text { Traits (remaining } \\
11 \text { items) } \\
\text { KMO: } .793 \\
\text { Variance: } 57 \%\end{array}$ & $\begin{array}{l}\text { Cron. } \\
\text { Alpha }\end{array}$ & $\begin{array}{l}\text { Impulsive } \\
\text { Behavior } \\
\text { (remaining } \\
21 \text { items) } \\
\text { KMO: .774 } \\
\text { Variance: } 54 \% \\
\end{array}$ & $\begin{array}{l}\text { Cron. } \\
\text { Alpha }\end{array}$ & 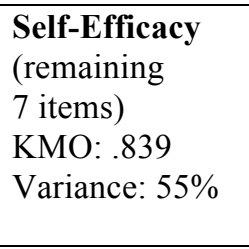 & $\begin{array}{l}\text { Cron. } \\
\text { Alpha }\end{array}$ \\
\hline $\begin{array}{l}\text { 1. Factor: } \\
\text { Machiavellianism }\end{array}$ & .797 & $\begin{array}{l}\text { 1. Factor: } \\
\text { Negative Urgency }\end{array}$ & .855 & $\begin{array}{l}\text { 1. Factor: Self- } \\
\text { Efficacy }\end{array}$ & .859 \\
\hline $\begin{array}{l}\text { 2.Factor: } \\
\text { Narcissism }\end{array}$ & .757 & $\begin{array}{l}\text { 2.Factor: } \\
\text { Sensation-seeking }\end{array}$ & .821 & & \\
\hline $\begin{array}{l}\text { 3.Factor: } \\
\text { Psychopathy }\end{array}$ & .745 & $\begin{array}{l}\text { 3.Factor: Lack of } \\
\text { Premeditation }\end{array}$ & .743 & & \\
\hline & & $\begin{array}{l}\text { 4.Factor: Lack of } \\
\text { perseverance }\end{array}$ & .725 & & \\
\hline
\end{tabular}

After the exploratory factor analysis, the confirmatory factor analysis has been conducted by Lisrel 8.8 for all scales. Goodness of fit indexes is presented in Table 2. It can be seen that all of the fit indexes fall within the acceptable ranges (SchermellehEngel et al., 2003: 52; Meydan and Şeşen, 2011: 35).

Table 2. Goodness of Fit Indexes of the Scales

\begin{tabular}{lccccccccc}
\hline Variables & $\chi^{\mathbf{2}}$ & d.f. & $\begin{array}{c}\chi^{\mathbf{2}} / \mathbf{d f} \\
\leq \mathbf{5}\end{array}$ & $\begin{array}{l}\text { GFI } \\
\mathbf{2 . 8 5}\end{array}$ & $\begin{array}{l}\text { AGFI } \\
\mathbf{2 . 8 0}\end{array}$ & $\begin{array}{l}\text { CFI } \\
\mathbf{2 . 9 0}\end{array}$ & $\begin{array}{l}\text { IFI } \\
\mathbf{2 . 9 0}\end{array}$ & $\begin{array}{l}\text { NNFI } \\
\mathbf{2 . 9 0}\end{array}$ & $\begin{array}{l}\text { RMSEA } \\
\leq \mathbf{0 . 0 8}\end{array}$ \\
\hline $\begin{array}{l}\text { Dark Trait } \\
\text { Personality }\end{array}$ & 47.75 & 32 & 1.49 & 0.95 & 0.92 & 0.98 & 0.98 & 0.97 & 0.050 \\
\hline Self-Efficacy & 12.34 & 8 & 1.54 & 0.98 & 0.95 & 0.99 & 0.99 & 0.99 & 0.052 \\
\hline $\begin{array}{l}\text { Impulsive } \\
\text { Behavior }\end{array}$ & 116.29 & 97 & 1.19 & 0.93 & 0.90 & 0.97 & 0.98 & 0.97 & 0.032 \\
\hline
\end{tabular}

\subsection{Data Analysis}

SPSS for Windows 20.0 and Lisrel 8.80 programs were used to analyze the obtained data. After the exploratory and confirmatory analyses, descriptive statistics such as means, standard deviations and pearson correlation analysis of the study variables were examined. Following that, structural equation modelling (SEM) was used to conduct a test of the variables in the research model to examine to what extent it is consistent with the data. 


\section{RESEARCH FINDINGS}

\subsection{Respondent Profile}

$53 \%$ of the employees were male and $47 \%$ were female. $49 \%$ of the employees were between the ages $17-25,34 \%$ of them were between the ages $26-34$. Whereas $17 \%$ of them were older than 35 . In terms of education level, $41 \%$ had a high school and primary school education, $36 \%$ of them had a bachelor's and graduate degree, $\% 23$ of them had a vocational school education. From the working unit perspective, $35 \%$ of the employees were working in front office department, $25 \%$ of them were working in other units such as guest relation, technical, human resource and accounting. \%19 of them were working in food and beverage department and \%11 of the employees were working in housekeeping department. $47 \%$ of the participants have been working for between 1-3 years and 37\% of them have been working for more than 4 years, while $16 \%$ of them have been working for less than 1 year in the same hotel.

\subsection{Descriptive Analyses}

In the scope of the descriptive analyses, means, standard deviations and correlations have been conducted which are related to dark trait personality, selfefficacy and impulsive behaviors. The values are given in Table 3.

Table 3. Means, standard deviations and correlations of the study variables

\begin{tabular}{lccllllll}
\hline & Mean & S.S & 1 & 2 & 3 & 4 & 5 \\
\hline Machiavellianism & 2.91 & .85 & 1 & & & & & \\
Narcissism & 3.22 & .86 & $.438^{* *}$ & 1 & & & & \\
Psychopathy & 2.78 & .87 & $.423^{* *}$ & $.367^{* *}$ & 1 & & & \\
Self-Efficacy & 3.93 & .72 & $.277^{* *}$ & $.466^{* *}$ & $.162^{*}$ & 1 & & \\
Impulsive Behavior & 2.45 & .47 & $.013^{* *}$ & $.123^{*}$ & $.257^{* *}$ &.$-209^{* *}$ & 1 & \\
\hline$* * p<0.01 * p<0.05$ & & & & & & &
\end{tabular}

As can be seen in Table 3, the results of correlation analysis show that the dimensions of dark personality traits which are labeled as psychopathy $(\mathrm{r}=.257$, $\mathrm{p}<0.01$ ); are positively related to the employees' impulsive behavior levels. Whereas narcissism is negatively related to the $(\mathrm{r}=-.123, \mathrm{p}<0.05)$ employees' impulsive behavior levels, machiavellianism has no significant relationship with the impulsive behaviors $(r=.013, p>0.05)$. On the other hand self-efficacy belief of employees $(r=-.209, p<0.01)$ are negatively related to impulsive behaviors. In this context, it can be expected that employees individual characteristics such as narcissism, psychopathy and self-efficacy may affect their impulsive behavior levels.

\subsection{Measurement Model}

For the verification of the model, two step approach by Anderson and Gerbing (1988) has been used. According to this approach, prior to testing the hypothesized structural model, first the research model needs to be tested to reach a sufficient goodness of fit indexes. The results of the measurement model were; $x^{2}$ : 518.93 ; df: 348; $\mathrm{x}^{2} / \mathrm{df}$; 1.49; RMSEA: 0.050; GFI: 0.85; IFI: 0.96; CFI: 0.95; NFI: 0.94; NNFI: 0.95 . These values indicate that measurement model is acceptable (Schermelleh-Engel et al., 2003: 52; Meydan and Şeşen, 2011: 37). 


\subsection{Structural Equation Model}

After demonstrating that the measurement model is acceptable, structural equation modeling was applied to test the hypotheses for the causal relationships in the research model. The results of the structural equation model were; $\mathrm{x}^{2}: 383.66 ; \mathrm{df}: 214 ; \mathrm{x}^{2} / \mathrm{df}$; 3.16; GFI: 0.86; RMSEA: 0.063; IFI: 0.94; CFI: 0.94; NFI: 0.93; NNFI: 0.94. These results indicate that structural model is acceptable (Schermelleh-Engel et al., 2003: 52; Meydan and Şeşen, 2011: 37). According to the results of structural equation model, the path parameter and significance levels show that narcissism has a negative and significant effect on employees' impulsive behaviors $(\gamma=-0.52$; $t$-value $=-2.09)$, so $\mathrm{H}_{1}$ hypothesis was supported. However, research resulsts indicate that psychopathy has a positive and significant effect on employees' impulsive behaviors $(\beta=0.43 ; \mathrm{t}=2.32$; $\mathrm{p}<0.01)$ and $\mathrm{H}_{3}$ hypothesis was supported. It was also found out that employees' selfefficacy belief levels has a negative and significant effect on impulsive behaviors $(\beta=-$ $0.57 ; \mathrm{t}=-3.04 ; \mathrm{p}<0.01)$, so $\mathrm{H}_{4}$ hypothesis was supported. On the other hand, machiavellianism has no significant effect on employees' impulsive behaviors and $\mathrm{H}_{2}$ hypothesis was not supported.

Figure 2. Supported Structural Model and Path Coefficients

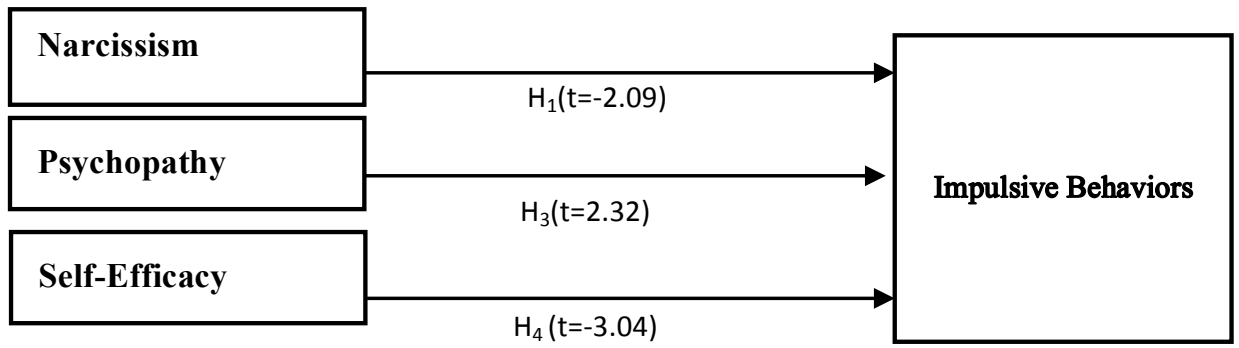

\section{CONCLUSION}

Impulsive behaviors are considered as unfavorable and antisocial attitudes and actions which likely to have a harmful effect on individuals and their social environment. These behaviors emerge from based on the internal and external stimuli that individuals encounter in their work and social lives. In other words, if individuals are exposed to some internal and external stimuli, they may behave in an unplanned manner, be lack of perseverance, and act impulsively and imprudently that lead to impulsive behaviors. In today's modern working area, impulsive behaviors are considered as one of most frequently occurring problems in organizational and social environment due to the changing in employment conditions, quality of life, values, relationships and individual characteristics. In some cases, individuals are forced to exhibit impulsive acts because of the complex situations or actions, which requires spontaneous decisions and needed to be handled in a quick manner. However, it can be inferred that impulsive behaviors depend on the present conditions that individuals encountered in their work lives and social environments. Besides, it is asserted that also impulsive behaviors emerge based on the individual characteristics such as personality traits, predisposition to take risk, self-esteem levels, internal and external locus of control and self-efficacy belief and etc. Accordingly, as the scope of the study, it is 
aimed to examine some individual antecedents of impulsive behaviors such as dark trait personality traits and self-efficacy belief. Based on the importance of adverse human behaviors and attitudes on organizational outcomes, it is needed to identify the antecedents of impulsive behaviors as for understanding how could be decreased these behaviors.

As a result of the research findings, it has been found that some dimensions of dark personality trait and self-efficacy belief have impact on impulsive behaviors of employees. In other words, one of the dimension of dark personality trait which labelled as a narcissism has a significant and negative effect on employees' impulsive behaviors. According to this result, it is possible to express that employees who have a narcissism trait have no tendency to exhibit without thinking and planning or suddenly due to the desiring a positive image on others and also need to acquire power, prestige and status. In contrast, employees who possess a psychopathy have a tendency to exhibit impulsive behaviors. Because psychopathic employees have some features such as insensitivity, thoughtlessness, low level of anxiousness, and disloyalty, it is expected them to be more thrill seekers. However, research results indicate that self-efficacy beliefs have decreased employees' impulsive behavior levels. Therefore, based on the analysis results of employees who are self-confidence and self-sufficiency, it can be said that these people are more self-conscious. As a result, they refrain from acting without planning and thinking or they refrain from immediate responses. Besides, research results revealed that the dimension of dark personality trait which is addressed as a machiavellianism has no significant effect on impulsive behaviors. Based on the machiavellianism have a disposition to behave in a self-interested and deceptive way, they demonstrate more thoughtful and foreseen attitudes instead of being unplanned and impatient.

As it can be seen from the results, dark traits of narcissism and psychopathy, and self-efficacy belief affect employees' impulsive behaviors. These results indicate that, while psychopathy leads to an increase in impulsive behavior, narcissism and selfefficacy leads" to a decrease in this behavior under the scope of hotel establishments. Since dark personality trait is regarded as an inevitable component of today's working environment and viewed as one of the frequently encountered problems, organizations need to reduce impulsive behaviors by maintaining favorable employment conditions. In other words, it is suggested that impulsive behaviors of psychopathic employees may be diminished through some positive work-life components such as rewards, well compensation, promotion and self-development opportunities. For future studies, it is recommended that the research model can be tested on other service sectors which human attitudes and behaviors have greater importance such as health, education and transportation. Moreover, the research model can be redesigned by adding some other variables which are tought to be organizational antecedents of impulsive behaviors such as organizational climate, quality of work life and human resource management practices and etc. Besides, it can be questioned whether some factors like self-esteem, locus of control and risk aversion may be mediating variables or not. 


\section{REFERENCES}

Anderson, J.C. and Gerbing D.W. (1988). Structural Equation Modelling in Practice: A Review and Recommended Two-Step Approach. Psychological Bulletin, 3 (3), 411-423.

Bandura, A. (1997). Self-efficacy: The exercise of control. New York: W. H. Freeman\&Co, Publishers.

Bausch, S., Michel, A. and Sonntag, K. (2014). How gender influences the effect of age on self-efficacy and training success, International Journal of Training and Development, Vol. 18, No. 3, 171-187.

Borgognia, L., Russo, S.D., Miraglia, M. and Vecchionea, M. (2013). The role of selfefficacy and job satisfaction on absences from work, Revue européenne de psychologie appliquée, 63, 129-136.

Churchill, S. and Jessop, D.C. (2011). Reflective and Non-Reflective Antecedents of Health-Related Behaviors: Exploring the Relative Contributions of Impulsivity and Implicit Self-Control to the Prediction of Dietary Behaviors, British Journal of Health Psychology, Vol. 16, 257-272.

Crysel, L.C., Crosier, B.S. and Webster, G.D. (2013). The Dark Triad and risk behavior. Personality and Individual Differences, 54, 35-40.

Eysenck, S. B. G. and Eysenck, H. J. (1977). The place of impulsiveness in a dimensional system of personality description. British Journal of Social and Clinical Psychology, 16, 57-68.

Farmer, R.F. and Golden, J.A. (2009). The Forms and Functions of Impulsive Actions: Implications for Behavioral Assessment and Therapy, International Journal of Behavioral Consultation and Therapy, Vol. 5, No.1, 12-30.

Gambin, M. and Święcicka, M. (2015). Relationships of self-efficacy beliefs to executive

functions, hyperactivity-impulsivity and inattention in school-aged children, Polish Journal of Applied Psychology, Vol. 13(1)

Garofalo, C., Velotti, P., Callea, A., Popolo, R., Salvatore, G., Cavallo, F. and Dimaggio, G. (2018). Emotion Dysregulation, Impulsivity and Personality Disorder Traits: A Community Sample Study, Psychiatry Research, Vol. 266, 186-192.

Heijnis, T. (2009). The Dark Side of Personality and Counterproductive Behavior, Unpublished Master Thesis, University of Amsterdam, Netherland.

Herman, A.M., Critcley, H.D. and Duka, T. (2018). The Role of Emotions and Physiological Arousal in Modulating Impulsive Behaviour, Biological Psychology, Vol. 133, 30-43.

Hogan, R. and Hogan, J. (2001). Assessing Leadership: A View from the Dark Side, International Journal of Selection and Assessment, 9 (1/2), 40-51.

Iskandar, T.M. and Sanusi, Z.M. (2011). Assessing the Effects of Self-Efficacy and Task Complexity on Internal Control Audit Judgment, Asian Academy of Management Journal of Accounting and Finance, Vol. 7, No. 1, 29-52. 
Jha, S.S. and Nair, S.K. (2008). Influence of Locus of Control, Job Characteristics and Superior-Subordinate Relationship on Psychological Empowerment, A Study in Five Star Hotels, Journal of Management Research, Vol. 8, No. 3, 147-161.

Jonason, P.K., Li, N.P. and Buss, D.M. (2010). The Costs and Benefits of the Dark Triad: Implications for Mate Poaching and Mate Retention Tactics, Personality and Individual Differences, 48, 373-378.

Jonason, P.K. and Webster, G.D. (2012). A Protean Approach to Social Influence: Dark Triad Personalities and Social Influence Tactics, Personality and Individual Differences, 52, 521-526.

Jonason, P.K., Wee, S. and Li, N. (2015). Competition, Autonomy, and Prestige: Mechanisms through which the Dark Triad Predict Job Satisfaction, Personality and Individual Differences, 72, 112-116.

Jones, D.N. and Paulhus, D.L. (2011). The role of impulsivity in the Dark Triad of personality, Personality and Individual Differences, Vol. 51, 679-682.

Jones, D.N. and Paulhus, D.L. 2014. Introducing the Short Dark Triad (SD3): A Brief Measure of Dark Personality Traits. Assessment, 21 (1), 28 -41.

Jovičić, A., Milanović, T., Todorović M. and Vujičić, D. (2011). The Importance of Fitting Personality Dimensions and Job Characteristics in Employees in the Hotel Management, TURIZAM, Vol. 15, Iss. 3, 119-131.

Justice, A. (2016). The Relationship of Empathy and Impulsivity to The Dark Triad of Personality, Thesis in Clinical Psychology, Abilene Christian University, Teksas.

Kaiser, R.B., LeBreton, J.M. and Hogan, J. (2013). The Dark Side of Personality and Extreme Leader Behavior, Applied Psychology: An International Review, doi: 10.1111/apps.12024.

Kanten P. 2014. The Antecedents of Job Crafting: Perceived Organizational Support, Job Characteristics and Self-Efficacy. European Journal of Business and Social Sciences, 3: 113-128.

Kanten, P., Yeşiltaş, M. and Arslan, R. (2015). Kişiliğin Karanlık Yönünün Üretkenlik Karşıtı İş Davranışlarına Etkisinde Psikolojik Sözleşmenin Düzenleyici Rolü. Atatürk Üniversitesi İktisadi ve İdari Bilimler Dergisi, 29 (2), 365-391.

Karatepe, O.M. (2014). The Effects of Coworker and Perceived Organizational Support on Hotel Employee Outcomes: The Moderating Role of Job Embeddedness, Journal of Hospitality \& Tourism Research, Vol. 36, No. 4, 495-516.

Koehn, M.A., Okan, C. and Jonason, P.K. (2018). A primer on the Dark Triad traits, Australian Journal of Psychology, 1-9.

Kowalski, R. M. (2001). Behaving badly: Aversive behaviors in interpersonal relationships. Washington, DC: APA press.

Lynam, D.R. and Miller, J.D. (2004). Personality Pathways to Impulsive Behavior and Their

Relations to Deviance: Results from Three Samples, Journal of Quantitative Criminology, Vol. 20, No. 4, 319-341. 
Magid, V. and Colder, C.R. (2007). The UPPS Impulsive Behavior Scale: Factor structure and associations with college drinking, Personality and Individual Differences, Vol. 43, 1927-1937.

Malesza, M. and Ostaszewski, P. (2016). Dark side of impulsivity - Associations between the Dark Triad, self-report and behavioral measures of impulsivity, Personality and Individual Differences, Vol. 88, 197-201.

Massie, K.P. (2006). In The Dark about Light: The Effects of Artificial Illumination on Impulsivity, Thesis in Experimental Psychology, Villanova University, Philadelphia.

Meydan, C.H. and Şeşen, H. (2011). Yapısal Eşitlik Modellemesi AMOS Uygulamaları. Ankara: Detay Yayıncılık.

Modic, D., Palomäki, J., Drosinou, M. and Laakasuo, M. (2018). The dark triad and willingness to commit insurance fraud, Cogent Psychology, 5, 1-12.

Moscoso, S. and Salgado, J.F. (2004). Dark Side Personality Styles as Predictors of Task, Contextual, and Job Performance, International Journal of Selection and Assessment, Vol. 12, No. 4, 356-362.

Nguyen, R., Brooks, M., Bruno, R. and Peacock, A. (2018). Behavioral measures of state impulsivity and their psychometric properties: A systematic review, Personality and Individual Differences, Vol. 135, 67-79.

O’Boyle, Jr., E.H., Forsyth, D.R., Banks, G.C. and McDaniel, M.A. (2012). A MetaAnalysis of the Dark Triad and Work Behavior: A Social Exchange Perspective, Journal of Applied Psychology, 97 (3), 557-579.

Paulhus, D.L. and Williams, K.M. (2002). The Dark Triad of personality: Narcissism, Machiavellianism, and Psychopathy", Journal of Research in Personality, 36, 556-563.

Rauthmann, J.F. and Kolar, G.P. (2013). The Perceived Attractiveness and Traits of the Dark Triad: Narcissists are Perceived as hot, Machiavellians and Psychopaths not, Personality and Individual Differences, 54, 582-586.

Reynolds, B., Ortengren, A., Richards, J.B. and Wit, H. (2006). Dimensions of Impulsive Behavior: Personality and Behavioral Measures, Personality and Individual Differences, Vol. 40, 305-315.

Rosen, P.J. (2010). Examining the Relationship between Self-Efficacy and Stimulus processing, Honors Projects (Psychology), Paper 136.

Schermelleh-Engel, K.,Moosbrugger H., and Müller, H. 2003. Evaluating the fit of structural equation models: Tests of significance and descriptive goodness-of-fit measures, Methods of Psychological Research, 8(2), 23-74.

Schwarzer, R. and Jerusalem, M. 1995. Generalized Self-Efficacy scale. In J. Weinman, S. Wright and M. Johnston, Measures in health psychology: A user's portfolio, "Causal and control beliefs", Windsor, UK: NFER-NELSON.

Simmen-Janevska, K., Brandstätter, V. and Maercker. A. (2012). The overlooked relationship between motivational abilities and posttraumatic stress: a review. European Journal of Psychotraumatology, 3:1. 
Simosi, M. (2012). The moderating role of self-efficacy in the organizational culturetraining transfer relationship, International Journal of Training and Development, Vol. 16, No. 2, 92-106.

Song, Z. and Chon, K. (2012). General self-efficacy's effect on career choice goals via vocational interests and person-job fit: A mediation model, International Journal of Hospitality Management, 31, 798-808.

Spain, S.M., Harms, P. and Lebreton, J.M. (2014). The Dark Side of Personality at Work, Journal of Organizational Behavior, Vol. 35, 41-60.

Stahl, C., Voss, A., Schmitz, F., Nuszbaum, M., Tüscher, O., Lieb, K. and Klauer, K.C. (2014). International Journal of Behavioral Consultation and Therapy, Journal of Experimental Psychology: General, Vol. 143, No. 2, 850-886.

Stanford, M.S., Mathias, C.W., Dougherty, D.M., Lake, S.L., Anderson, N.E. and Patton, J.H. (2009). Fifty years of the Barratt Impulsiveness Scale: An Update and Review, Personality and Individual Differences, Vol. 47, 385-395.

Tüzün, İ.K., Çetin, F. and Basım, H.N. (2017). Deviant employee behavior in the eyes of colleagues: the role of organizational support and self-efficacy, Eurasian Bus. Rev., Vol. 7, 389-405.

Vasconcelos, S.C., Frazão, I.S., Sougey, E.B., Souza, S.L., Silva, T.P.S. and Lima, M.D.C. (2018). Assessment tools for the measurement of the self-efficacy of drug users: protocol for a systematic review, BMJ Open 2018;8:e019019. doi:10.1136/bmjopen-2017-019019, 1-4.

Wai, M. and Tiliopoulos, N. (2012). The Affective and Cognitive Empathic Nature of the Dark Triad of Personality, Personality and Individual Differences, 52, 794799.

Whiteside, S.P. and Lynam, D.R. (2001). The Five Factor Model and Impulsivity: Using a Structural Model of Personality to Understand Impulsivity, Personality and Individual Differences, Vol. 30, 669-689.

Wu, J. and Lebreton, J.M. (2011). Reconsidering The Dispositional Basis of Counterproductive Work Behavior: The Role of Aberrant Personality, Personnel Psychology, 64, 593-626.

Zuckerman, M., Kuhlman, D. M., Thornquist, M., \& Kiers, H. (1991). Five (or three) robust questionnaire scale factors of personality without culture. Personality and Individual Differences, 12, 929-941. 